\title{
O PROCESSO DE CONCENTRAÇÃO DO CAPITAL NO ENSINO SUPERIOR PRIVADO-MERCANTIL BRASILEIRO
}

\author{
TARcísio Luiz Pereira ${ }^{1}$
}

\begin{abstract}
RESUMO: Este artigo pretende discutir e analisar, a partir das leis do movimento do modo de produção capitalista, o processo de concentração do capital no Ensino Superior privado-mercantil, que vem ocorrendo nas últimas décadas no Brasil. Para tanto, a investigação se debruçou sobre expansão, aquisições e fusões ocorridas no setor que possibilitaram o surgimento de monopólios e oligopólios com significativo aporte do Estado brasileiro. Nesse cenário, tem surgido constante reestruturação, por conta da dinâmica do capitalismo na adaptação e na readaptação de novos e velhos nichos de mercado de acordo com os lucros obtidos.
\end{abstract}

Palavras-chave: Ensino Superior. Capital. Estado. Políticas.

\section{THE CAPITAL CONCENTRATION PROCESS IN BRAZILIAN PRIVATE HIGHER EDUCATION}

\begin{abstract}
This article intends to discuss and analyze, based on the laws of the movement of the capitalist mode of production, the process of concentration of capital in private higher education, which has been occurring in the last decades in Brazil. To this end, the investigation focused on the expansion, acquisitions, and mergers that occurred in the sector, which enabled the emergence of monopolies and oligopolies with a significant contribution from the Brazilian State. In this scenario, constant restructuring has arisen, due to the dynamics of capitalism in adapting and re-adapting new and old market niches according to the profits obtained.
\end{abstract}

Keywords: Higher education. Capital. State. Policies.

\section{EL PROCESO DE CONCENTRACIÓN DE CAPITAL EN LA EDUCACIÓN SUPERIOR PRIVADA BRASILEÑA}

RESUMEN: Este artículo pretende discutir y analizar, a partir de las leyes del movimiento del modo de producción capitalista, el proceso de concentración de capital en la educación superior privada, que ha venido ocurriendo en las últimas

Este artigo é parte de pesquisa de doutorado intitulada Monopolização do Ensino Superior Privado no Brasil por meio de Processos de Fusões e Aquisições: o Grupo UNIESP em Questão, orientada por Silvia Helena Andrade de Brito, no Programa de Pós-graduação em Educação da Faculdade de Educação da Universidade Federal de Mato Grosso do Sul (FAED/UFMS), campus de Campo Grande (MS).

O projeto foi subsidiado pela CAPES no formato bolsista. Código de Financiamento 001.

1.Universidade Federal de Mato Grosso do Sul - Centro Pedagógico de Três Lagoas- Programa de Pós-graduação em Educação - Três Lagoas (MS), Brasil. E-mail: tluizp@gmail.com. 
décadas en Brasil. Para eso, la investigación se centró en expansión, adquisiciones y fusiones ocurridas en el sector, que posibilitaron el surgimiento de monopolios y oligopolios con una importante contribución del Estado brasileño. En este escenario, ha surgido una reestructuración constante, debido a la dinámica del capitalismo en la adaptación y readaptación de nuevos y viejos nichos de mercado en función de los beneficios obtenidos.

Palabras-clave: Educación superior. Capital. Estado. Políticas.

\section{Introdução}

A

s contrarreformas nas instituições de Ensino Superior têm sido amplamente discutidas em todo o mundo, principalmente a partir da década de 1990, período associado à globalização do capital e à expansão do chamado capitalismo financeiro - em que a educação superior começa a ser tratada como mercadoria, não mais como bem público que deve ser assegurado pelos Estados. Isso levou a um rápido crescimento das instituições privadas-mercantis de Ensino Superior, particularmente nos países em desenvolvimento, onde as deficiências no sistema de Ensino Superior público são maiores ${ }^{1}$. Diante desse processo de globalização da economia, de maior abertura comercial e de novas tecnologias, crescem as afirmações de que a formação acadêmica se torna fundamental para aumentar a competitividade entre países. Em um ambiente cada vez mais competitivo, a educação, especialmente a superior, passa a ser atrativo para os investidores do mercado financeiro internacionalmente.

Tomada como artigo mercadológico, a educação superior "foi amplamente debatida em fóruns econômicos mundiais nas últimas décadas, o que resultou em documentação do Banco Mundial”2 (PEREIRA, 2017, p. 76) e de outras organizações congêneres, afirmando que "esta área deve ser compreendida como um setor atrativo para o investimento e a acumulação capitalista” (BANCO MUNDIAL, 2009). A educação superior passa, então, a assumir

[...] a forma de um processo educacional voltado para uma formação humana reducionista, predominantemente profissionalizante, realizada por intermédio de uma lógica profissionalizante e privatista ou mercantilizada (SGUISSARDI; SILVA JÚNIOR, 2009, p. 32 apud PEREIRA, 2017, p. 77).

Segundo Brunner (2006, apud PEREIRA, 2017, p. 77), não são apenas os grupos empresariais, companhias e players (na linguagem do mercado) que atuam no campo educacional, abrem seu capital e passam a obter recursos via valorização de ações na Bolsa de Valores. De acordo com o autor, o setor do Ensino Superior vem passando por um conjunto grande e complexo de mudanças produzidas por uma gama de fatores, entre as quais: as mudanças no papel dos governos em relação à educação superior, associadas à difusão de um discurso de mercado; a massificação da educação superior; o crescente número de mantenedores privados da educação superior e da pesquisa; e o surgimento de um mercado global para os serviços de educação superior e de conhecimento.

Com o processo de financeirização do capitalismo mundial e o favorecimento às atividades privatistas e econômicas por meio da flexibilização das legislações na área da educação, o "mercado educacional" passa a contar com aportes financeiros dos fundos de investimento, que incidem como protagonistas das grandes movimentações de capitais e do gerenciamento monetário no setor do Ensino Superior privado-mercantil. 
Foi na década de 1990, com a descompartimentalização dos mercados financeiros nacionais ${ }^{3}$, ou seja, "com a abertura do mercado de títulos públicos aos operadores estrangeiros, que o setor bancário perdeu força para os fundos de investimentos” (CHESNAIS, 2005 apud PEREIRA, 2017, p. 79).

\begin{abstract}
Nota-se que o ressurgimento dessa forma de capital financeiro, representado pelos fundos privados, promoveu o reaparecimento dos mercados especializados nos anos 2000, que, por sua vez, possibilitam liquidez ao capital portador de jurosNo Brasil é no artigo 209, da Constituição Federal de 1988, que encontramos a legitimação por meio do Estado do funcionamento das instituições de Ensino Superior privadas no território nacional: o ensino é livre à iniciativa privada, atendidas as seguintes condições: I - cumprimento das normas gerais da educação nacional; II - autorização e avaliação de qualidade pelo Poder Público (PEREIRA, 2017, p. 79-80).
\end{abstract}

Em 1995, o art. 7- A, da Lei n. 9.131, de 1995, já referendava que "as pessoas jurídicas de direito privado, mantenedoras de instituições de Ensino Superior [...] poderão assumir qualquer das formas admitidas em direito, de natureza civil ou comercial [...]" (BRASIL, 1995) e serão regidas pelo disposto no Código Civil Brasileiro.

Com a promulgação da Lei de Diretrizes e Bases da Educação Nacional (LDB 9.394), em 1996, o setor do Ensino Superior privado ganha ainda mais força no território nacional. Com a reafirmação do artigo 209 da Constituição Federal no artigo $7^{\circ}$ da nova lei da educação, lê-se: “o ensino é livre à iniciativa privada” (BRASIL, 1997).

A legislação passa a admitir, assim, que pessoas jurídicas de direito privado (ou seja, empresários e investidores), mantenedoras de instituições de Ensino Superior, possam assumir qualquer das formas admitidas em direito, de natureza civil ou comercial, criando um "novo setor da economia", que passa a contar com subsídios estatais e com vultuosos recursos advindos do denominado capital financeiro ${ }^{4}$. Cabe destacar que os fundos de investimentos privados, como forma de aplicação financeira, têm por objetivo promover rentabilidade futura a seus acionistas. Tais fundos são formados por vários investidores, que atuam por meio do capital portador de juros, denominado por Marx (2012) capital fictício, com o qual se negociam ações nas Bolsas de Valores.

Para Marx (2012 apud PEREIRA, 2017, p. 79), esse "capital portador de juros", como forma capital, "não pode de forma nenhuma estar separado do desenvolvimento do capital industrial, onde ocorre a produção de mais-valia e a subsunção do trabalho ao capital” (CHESNAIS, 2005, p. 55).

É interessante notar ainda que o Código Civil Brasileiro, entre os arts. 42 e 52, conceitua as instituições na condição de pessoa jurídica e as subdivide em: associações; sociedades; fundações; organizações religiosas; partidos políticos; e empresas individuais de responsabilidade limitada - todas podendo, amparadas pela Lei n. 9.131, de 1995, adquirir instituições de Ensino Superior.

Ainda de acordo com o Código Civil, uma instituição mantenedora que tenha caráter estrangeiro pode funcionar normalmente no país: "mediante autorização do Poder Executivo, a sociedade estrangeira admitida a funcionar no país pode nacionalizar-se, transferindo sua sede para o Brasil” (BRASIL, 2002, seção III - Da Sociedade Estrangeira).

Com isso, o Estado brasileiro vai se estruturando burocraticamente no sentido de flexibilizar e regulamentar acordos e ajustes às alianças formadas com o setor empresarial, seja nacional, seja estrangeiro, o que, aos mantenedores do Ensino Superior privado, resultou, a partir dos anos 2000, numa maior possibilidade de expansão dos negócios no país.

Pode-se dizer que o marco inicial deste processo se deu em 2006, com a aquisição da Universidade Anhembi Morumbi de São Paulo-SP pela empresa estadunidense Laureate International, controlada pelo fundo KKR . Em 2014, a Estácio de Sá, passa a ser controlada pela GP; a Anhanguera, pelo Banco Pátria ${ }^{6}$; e a Kroton, pela Advent International7 ${ }^{7}$ (PEREIRA, 2017, p. 78). 
Não se pode deixar de observar que o atual modo de produção capitalista contou com abundantes e variadas formas de ajuda externa ao longo do século XX e do início do século XXI, entre elas as intervenções estatais, demonstrando, assim, sua insuficiência para garantir a estabilidade permanente e o crescimento contínuo do sistema.

Para Mészáros, está em curso uma crise estrutural do capital, que "se choca com os seus próprios limites intrínsecos" (2011, p. 8). "É precisamente a ausência necessária do Estado do sistema de capital”, enfatiza Mészáros, "que demonstra a (in)capacidade do capital de levar a lógica objetiva da irrefreabilidade do sistema até suas conclusões últimas" (MÉSZÁROS, 2011, p. 8). Maria Cristina Soares Paniago, em uma perspectiva análoga e complementar, afirma que, diante desse contexto, "o Estado passa a ser convocado como um complemento do mercado" (PANIAGO, 2000, p. 2).

Nesse sentido, as políticas expansionistas do Estado brasileiro passaram a ser sinônimo de privatizações, possibilitando, em ampla medida, que o setor privado transformasse o Ensino Superior num grande negócio, o qual resultou na formação de verdadeiros conglomerados educacionais por meio de processos de aquisições e fusões de faculdades, centros universitários e universidades.

\section{O Processo de Concentração do Capital no Ensino Superior Privado Brasileiro}

No cenário brasileiro, até os anos 2000, as instituições de Ensino Superior privadas (IESP) se encontravam predominantemente sob o controle de mantenedores de natureza familiar. A partir de 2008, houve um aumento na quantidade de fusões e aquisições realizadas no setor privado de ensino por intermédio de empresários e de fundos de investimentos nacionais e internacionais. Nesse contexto, enquanto o Estado promovia políticas públicas de incentivo à expansão do Ensino Superior privado no país, as IESP de pequeno e médio portes passaram a perder espaços e a serem adquiridas pelas grandes empresas desse setor (PEREIRA, 2017, p. 85).

Nos anos seguintes, houve um acelerado e intenso processo de mercantilização no setor e os fundos de investimentos, por meio da abertura que a legislação brasileira possibilitou ao capital estrangeiro, trouxeram, para a área da educação superior, mecanismos outrora relativos apenas às áreas industrial e empresarial e aos setores de comercio e serviços, como: gestão concentrada no valor; liquidez; rentabilidade; índices financeiros; planejamentos financeiros; gestão de negócios; técnicas de venda e persuasão de clientes, entre outros. Houve, portanto, uma drástica alteração na natureza das relações de trabalho e na oferta de ensino até então em curso, relacionada a um aprofundamento na proeminência do setor financeiro no controle do Ensino Superior:

O processo de expansão da educação superior no Brasil, que sempre teve fortes traços mercantis, a partir de 2007 inaugurou uma nova tendência no segmento privado, constatando um processo de compra e venda de instituições, com fusões que têm formado oligopólios educacionais, ou seja, com uma tendência à formação de número menor de grandes empresas que atuam num nicho mercadológico, no caso, o educacional, e que passam a ter um controle de parte cada vez maior do mercado da educação superior (CHAVES, 2010, p. 483). 
Tal processo de expansão e concentração do capital no Ensino Superior privado brasileiro, pautado na obtenção de lucro, foi desenvolvido sem o devido acompanhamento por parte da sociedade, ainda que haja órgãos governamentais que fiscalizem as empresas que buscam comprar outras organizações para se expandirem, como é o caso do Conselho Administrativo de Defesa Econômica - CADE, autarquia federal vinculada ao Ministério da Justiça (Lei n. 12.529/2011) (PEREIRA, 2017, p. 123).

O CADE é pautado pelo objetivo de defender a livre concorrência no mercado. No âmbito do Poder Executivo, a entidade é responsável pelas decisões e investigações relacionadas à matéria concorrencial e pelo fomento e a disseminação da cultura da livre concorrência. Um de seus objetivos principais é o combate ao crime contra a economia popular - ou seja, o CADE tem por princípio legal controlar as empresas que abusam do poder, seja em casos de monopólios, seja de oligopólios.

Ainda que o órgão tenha julgado e aprovado a entrada do Grupo Apollo no capital da Pitágoras/ Kroton, em 2001, foi a partir de 2007 que "o movimento de fusões e aquisições no setor do Ensino Superior se tornou significativo em termos de notificações ao Sistema Brasileiro de Defesa da Concorrência (SBDC)" (CADE, 2015, p. 27).

Nota-se que o auge das análises relacionadas aos processos de aquisições e fusões foi alcançado no período de 2011 a 2013, com 29 julgamentos desse tipo de processo. Até 2015, o órgão julgou e aprovou 62 atos de concentração no mercado de Ensino Superior privado e apenas um caso foi arquivado, porque os requerentes desistiram da operação. A ampla maioria foi aprovada sem restrições.

Neste sentido, apesar de o CADE ser um órgão federal pautado pelo objetivo de "investigar, em todo o território nacional, e, posteriormente, julgar cartéis e outras condutas nocivas" (CADE, 2015) - ou seja, “assumir a função de um conselho antitruste ${ }^{8 ”}$ (PEREIRA, 2017, p. 124) -, a instituição aprovou praticamente todos os processos julgados até 2015. Em outras palavras, a Lei Antitruste não repudia necessariamente o poder do mercado, nem torna inviável a formação de monopólios e/ou oligopólios no território nacional.

Cabe destacar que, apesar do cenário mundial apontar para uma crise estrutural ${ }^{9}$, a expansão do mercado de Ensino Superior no Brasil se manteve em processo de crescimento, fator esse decorrente do amparo concedido pelo Estado.

O Brasil passa a concentrar, com isso, os maiores grupos educacionais privados do mundo, com destaque para os grupos: Kroton/Anhanguera; Anima; Estácio; Ser Educacional; Devry; Laureate; e Universidade Paulista (UNIP) - representando um polo expressivo para o desenvolvimento desse setor mercadológico.

Considerando o aumento significativo do número de matrículas no Ensino Superior privado nos últimos anos, temos uma dimensão do tamanho e da influência desse mercado na história recente do país.

Segundo dados de matrículas da Sinopse Estatística da Educação Superior, do Instituto Nacional de Estudos e Pesquisas Educacionais Anísio Teixeira (INEP), o setor privado respondia, em 2005, por 3.260.967 matriculas e, em 2018, o número dobrou para 6.373.274. De um total de 8.450.755 matrículas (em 2018), incluindo o ensino de graduação presencial e a distância, o setor público respondeu por apenas 2.077.481 (1.324.984 no setor público federal; 660.854 nas instituições estaduais; e 91.643 nas instituições municipais). Ou seja, as matriculas se concentram, predominantemente, no setor privado, o qual respondeu por $75 \%$ do total de matriculas.

Cabe destacar que o aumento no número de matriculas no setor privado não correspondeu, em proporção, no mesmo período (2005 a 2018), ao aumento no número de instituições de ensino. Em 2005, havia 1.934 instituições privadas e, em 2018, um total de 2.238 instituições; ou seja, um aumento de 15.7\%, denotando concentração e monopolização do setor. 
Nesse contexto, pode-se dizer que "as leis do movimento do modo de produção capitalista" (Marx, 2012) encontraram, “[...] terreno fértil no Brasil, seja através da (des)regulamentação ou por meio da transferência de recursos públicos, que contribuem para o processo de reprodução ampliada do capital, contando com a participação fundamental do Estado" (TAVARES, 2014, p. 116).

O Ensino Superior privado-mercantil brasileiro se tornou, assim, um dos ramos mais rentáveis na economia nacional, em virtude, não apenas, de investimentos realizados pelos fundos de investimento, mas também pela abertura econômica dada pelo Estado, com uso expressivo de recursos públicos, sobretudo pelo Financiamento Estudantil (Fies).

Trata-se, pois, de uma dinâmica que articula a concentração do capital ${ }^{10}$, por meio da compra de empresas educacionais de pequeno e médio portes seguida de processos de reestruturação internos, redução de custos e racionalização administrativa e do uso de gestão claramente empresarial ${ }^{11}$, com fusões entre as grandes instituições desse setor. Fato é que as instituições privadas-mercantis de Ensino Superior têm adotado, na ampla maioria das situações, um ensino de qualidade discutível ${ }^{12}$, inclusive com o uso intensivo da EaD.

Há uma guerra explícita, sobretudo entre as maiores universidades, que procuram abocanhar parcelas cada vez maiores de jovens à procura de um curso superior. Essa competição se revela com maior ênfase no segmento das instituições privadas empresariais/comerciais, ou privadas stricto sensu, isto é, aquelas pertencentes a famílias, grupos empresariais, ou um único proprietário, para quem o ensino é fonte de lucro (BITTAR, 2001, p. 24).

De acordo com Sguissardi,

[...] as instituições de Ensino Superior privadas do país com fins lucrativos e, em especial, as mantidas por empresas de capital aberto e envolvidas no mercado acionário, [...] hoje, apresentam-se como o setor de maior rentabilidade dentre os setores atuantes na BM\&F Bovespa (2015, p. 103).

Sguissardi, acompanhando a evolução do índice do Ibovespa e do valor das ações, em 2013 e 2014, concluiu: "em dois anos, a Kroton teve uma valorização de suas ações na Bolsa de 314,87\%; a Estácio, 240,97\%; e a Anhanguera, nos dois anos que correram até 28 de março de 2014, 85,89\%” (2015, p. 122).

Merece destaque, a migração do capital movimentado no Ensino Superior para o nível básico de ensino. Nas últimas décadas, a educação básica vem sofrendo intenso ataque dos setores privatistas, tanto em sua estrutura financeira-organizacional, quanto em treinamento docente e na concepção de currículo.

De acordo com a Confederação Nacional dos Trabalhadores em Educação (CNTE),

[...] em 2015, o Supremo Tribunal Federal (STF) julgou constitucional a Lei n. 9.637/98, autorizando as escolas públicas a serem geridas por Organizações Sociais (OS), retirando, assim, a exclusividade do Poder Público em administrá-las. Já em 2017, a terceirização indiscriminada (Lei n. 13.429) e a Reforma Trabalhista (Lei n. 13.467), aliada à Lei das OS, avançam em inúmeras formas de contratos precários que poderão atingir todos os profissionais da educação escolar pública (professores, pedagogos e funcionários administrativos). Essa "nova" estrutura organizacional e de contratação de pessoal imposta à escola pública brasileira, além de estimular a terceirização de sua gestão para políticos-empresários que atuam na área educacional através de OS, também remontará à nefasta prática do nepotismo e de contratações políticas, que a Constituição Federal de 1988 tinha conseguido estancar. Um retrocesso sem 
precedentes! E, dando sequência à pavimentação da privatização e mercantilização da educação no nível básico, a "reforma" do Ensino Médio (Lei n. 13.415) visa criar reserva de mercado para as empresas educacionais especializadas na Educação Profissional, visto que mais da metade do currículo escolar dessa etapa poderá ser destinada às áreas de formação específica, com preponderância para a educação técnica e profissional aos estudantes das classes populares (CNTE, 2017, p. 747).

$\mathrm{Na}$ esteira desse processo, a gigante do Ensino Superior privado-mercantil no país, Kroton - que, de acordo com dados ${ }^{13}$ da Federação dos Professores do Estado de São Paulo (Fepesp), já conta com mais de 1 milhão e 200 mil estudantes presenciais, 819 mil na educação a distância e outros 290 mil escolares na educação básica -, quer abocanhar ainda mais no "mercado" da educação. Em 2019, o grupo Kroton se reestruturou e criou a holding Cogna Educação com quatro subsidiárias, cada qual focando em fatias diferentes do mercado da educação no país. Depois de um superlucro, advindo, principalmente, do financiamento de estudantes universitários pelo Prouni e pelo Fies, o alvo passa a ser a educação básica, com $\mathrm{EaD}$ e padronização de materiais didáticos.

Com a nova estrutura, a empresa separou sua operação em negócios próprios e serviços educacionais para terceiros. A unidade de prestação de serviços para outras faculdades agora chama-se Platos e a que atende outras escolas de educação básica será a Vasta/Somos. A subsidiária de colégios próprios será a Saber e o nome Kroton será mantido na divisão do Ensino Superior.

Em síntese, o capital investido e concentrado no Ensino Superior privado está em processo de expansão e reestruturação, que o impulsiona não apenas ao crescimento orgânico dos cursos superiores mantidos por ele, mas também à incorporação de outras mantenedoras de menor porte e de novos nichos de mercado como importante estratégia de investimento e lucratividade.

\section{Considerações Finais}

Como dito, a expansão do setor de Ensino Superior privado-mercantil no Brasil só foi possível com o aporte estatal, que possibilitou a entrada de capital advindo dos setores industriais e empresariais, não apenas brasileiro, mas também internacional, o que possibilitou a esse setor uma supervalorização de seus lucros - o que, nas palavras de Marx, traduz-se "como valor que valoriza a si mesmo" (2012, p. 184).

Nesse cenário, a pequena propriedade capitalista vem cedendo lugar a grandes corporações. Evidencia-se, desse modo, que o Ensino Superior privado-mercantil brasileiro vem cumprindo à risca as deliberações dos organismos internacionais, especialmente as do Banco Mundial ${ }^{14}$.

Embora não haja certezas relacionadas ao estabelecimento e à consolidação das instituições de Ensino Superior privado ao longo dos próximos anos, é possível prever, pelos resultados deste estudo, algumas tendências já em andamento, como:

[...] surgimento de novas forças competitivas e quebra do monopólio geográfico, regional e local no mercado do Ensino Superior privado, por meio de compra das IESP menores pelas grandes do setor; operação em um mercado global, cada vez mais desregulamentado da "indústria do conhecimento" e, por conseguinte, do "mercado educacional"; reestruturação da educação superior, implicando o desaparecimento de faculdades e universidades de pequeno e médio portes, ou seja, maior concentração no setor, com aporte expressivo de capital internacional; mudanças no modelo de ensino, com fortes influências do modelo adotado na produção 
industrial/empresarial; e, em função do uso maciço das novas tecnologias, a consolidação de uma "geração digital", com suas demandas e novos processos de relacionamentos e migração de capital investido no Ensino Superior para a educação básica e/ou outro nicho de mercado (PEREIRA, 2017, p. 186).

Desse modo, as formas de Ensino Superior privado podem se configurar cada vez mais desvinculadas, com professores e alunos ainda mais afastados da sala de aula e do processo de ensino-aprendizagem presencial e da pesquisa.

O cenário que se desenha, portanto, é o de predomínio de um Ensino Superior privado-mercantil ofertado pela integração das mídias eletrônicas com as sociais nos chamados "ambientes colaborativos", espaços de exploração da classe trabalhadora pelos players do setor.

Como enfatiza Harvey (2008), o capitalismo monopolista tem sobrevivido precisamente por manter esse movimento dialético e aceitar suas inevitáveis tensões, incluindo as crises que dele resultam, movendo-se de uma esfera de atividade a outra, de modo a promover um apoio mútuo entre os diferentes setores.

Assim, no Ensino Superior privado brasileiro, o capital se metamorfoseou num "movimento, num processo cíclico que percorre diferentes estágio" (MARX, 2012, p. 184). Nesse sentido, os lucros obtidos no setor percorreram diferentes formas e movimentos, "nos quais eles se conservam e, ao mesmo tempo, se valorizam, aumentando de tamanho" (MARX, 2012, p. 184).

Vale lembrar a previsão marxista: "Para o capitalista, tanto faz ter investido seu capital numa fábrica de ensinar, em vez de numa fábrica de salsichas, não altera nada na relação de produção" (MARX, 2012, p. 106). Ainda de acordo com Marx, as tendências do sistema capitalista são: a formação de monopólios; a centralização agigantada das bases produtivas capitalistas; a consolidação do mercado mundial; a abertura das fronteiras nacionais; as crises globais; o desemprego estrutural; a massificação da miséria; e a invasão mundial do capital.

Sendo assim, reconhecendo a realidade concreta, dialética e contraditória, cabe reafirmar a necessidade da (re)construção da luta na direção contra-hegemônica, tendo na educação as ferramentas para um projeto revolucionário de sociedade.

\section{Notas}

1. No Brasil, de acordo com Durham, esses resultados então associados à retomada, na década de 1990, do crescimento do Ensino Superior: "[d]e fato o crescimento nos últimos cinco anos foi surpreendente: $82,0 \%$ do total das matrículas. Como na década de 1970 , entretanto, o crescimento se deu basicamente no setor privado" (2003, p. 32-33). Também, como na década de 1970, "o setor público cresceu muito menos, 36,0\%" (DURHAM, 2003, p. 32-33). Para a autora, é possível relacionar esse declínio preocupante do peso relativo do setor público com o fato de a política para o Ensino Superior não ter incorporado propostas formuladas no próprio Ministério e pela Secretaria de Políticas Educacionais, as quais defendiam a criação de um sistema público de ensino de massa de qualidade que contrabalançasse o elitismo inerente à exclusiva concentração em universidades de pesquisa. "Apesar de todas as inovações, houve omissões importantes na política educacional recente que afetaram de modo particular o sistema público de Ensino Superior, no qual não foram solucionados os problemas estruturais que entravavam o seu funcionamento e a sua expansão" (DURHAM, 2003, 0. 32-33). Com isso, a democratização do ensino, com a absorção da demanda de caráter mais popular, continuou na dependência crescente do ensino privado de massa, para o qual essa continua a ser uma atividade muito lucrativa. (DURHAM, 2003, p. 32-33, grifo do autor). 
2. Relatório Anual de 2009 do Banco Mundial, Ano em Perspectiva.

3. O ano de 1994 é considerado referência nos debates da mundialização, pois foi a partir desse período que as bolsas de valores ganharam importância cada vez maior. Isso porque é nesses espaços que ocorre a compra de ações de grupos industriais pelas instituições financeiras (fundos de investimentos, fundos mútuos, fundos de pensão, companhias de seguro), apostando na lucratividade das empresas - trata-se de um momento axial, pois demarca a desintermediação e a perda do monopólio dos bancos no setor de crédito e investimentos. (IAMAMOTO, 2012).

4. Marx, no Livro 3, Volume 4, de O Capital, discute duas formas de capital, a fórmula geral do capital dinheiro produtor de juros (D-D'): o capital bancário e o capital fictício. Para Marx (2016), os juros são parte do lucro do capitalista industrial que é apropriado pelo capital financeiro (capital de crédito e capital fictício).

5. Fundada por três ex-executivos do banco Bear Stearns, Jerome Kohlberg e os primos Henry Kravis e George Roberts, foi batizada com as iniciais de seus sobrenomes. O KKR orquestrou uma das maiores aquisições alavancadas da história: em 1989, ao lado de fundos de pensão e outros bancos de investimento, comprou por US\$ 31,1 bilhões (US\$ 60 bilhões em valores atuais) a RJR Nabisco, um ícone americano. Além de marcas de cigarro como Winston Salem, a empresa produz os biscoitos Oreo, consumidos em todo o mundo (ISTOÉ..., 2014).

6. Em atividade há mais de 28 anos, Patria Investimentos é uma das maiores gerentes de investimentos alternativos com foco em ativos na América Latina, especialmente no Brasil. É pioneira em private equity no Brasil, construindo gradualmente sua carteira com a criação de novas empresas em infraestrutura, imobiliário, crédito e agronegócios. Disponível em: https:// translate.google.com.br/translate?hl=pt-BR\&sl=en\&u=http://www.patriainvestimentos.com.br/\&prev=search. Acesso em: 19 jun. 2019.

7. Fundada em 1984, a Advent International é uma das maiores empresas de private equity do mundo, com escritórios em quatro continentes e foco em aquisições e investimentos de capital em crescimento. Foi fundada, originalmente, em Boston, por Peter Brooke, em 1987, quando a empresa levantou US\$ 225 milhões de fundo na Rede Internacional, seu primeiro fundo de private equity institucional. A empresa elevou seu primeiro fundo europeu, em 1989, e abriu seu escritório em Londres. Advent continuou sua expansão na década de 1990, abrindo escritórios em Frankfurt e Milão. Em 1994, a Advent concluiu a angariação para o primeiro de uma série emblemática de fundos, como o Advent Global de Private Equity (GPE) II, com US \$ 415 milhões. Em 1996, a Advent expandiu para a América Latina com o fundo Advent Latin American Private Equity e abriu escritórios em Buenos Aires, Cidade do México e São Paulo. Disponível em: https://www.adventinternational.com. Acesso em: 19 jun. 2019.

8. Lei n. 12.529, de 30 de novembro de 2011.

9. “A crise estrutural do capital que começamos a experimentar nos anos 70 [...] significa simplesmente que a tripla dimensão interna da autoexpansão do capital exibe perturbações cada vez maiores. Ela não apenas tende a romper o processo normal de crescimento mas também pressagia uma falha na sua função vital de deslocar as contradições acumuladas do sistema" (MÉSZÁROS, 2008, p. 799).

10. De acordo com Bukharin, a concentração do capital na empresa individual expressa a forma inicial desse processo, predominante até o século XIX. Com o desenvolvimento das sociedades anônimas, passou-se a empregar os capitais de um grande número de patrões isolados, estratégia que lançou um golpe definitivo ao princípio da empresa individual e criou condições necessárias ao desenvolvimento dos grandes monopólios. Ao longo desse processo, a concentração dos capitais tomou nova forma, conhecida como "truste": "[a] acumulação do capital cessou de aumentar os capitais dos produtores individuais, transformando-se em meio de crescimento de capitais das organizações patronais” (BUKHARIN. 1917, p. 117).

11. Data dessa época o surgimento de novos atores no sistema de Ensino Superior no Brasil: os "assessores" e/ou "consultores". O fato poderia passar despercebido não fosse o papel que essa categoria de profissionais viria a desempenhar na transição de um modelo de organização da oferta privada de Ensino Superior marcadamente familiar para outro, baseado no anonimato do capital financeiro, que combina gestão empresarial, novas tecnologias de ensino-aprendizagem e o serviço Ensino Superior. Vale lembrar que a passagem entre os dois modelos ainda está em curso e que a coexistência deles é, em parte, responsável pelo caráter singular do processo de privatização do Ensino Superior no Brasil neste século (SAMPAIO, 2011, p. 16).

12. A qualidade dos cursos ofertados pelas universidades particulares não cresceu na proporção de seu financiamento público. Apenas $16 \%$ dos 448 centros universitários, faculdades e universidades cujas rnantenedoras receberam $80 \%$ de todo o valor gasto com Fies em 2014 tinham, naquele ano, índices de qualidade acima do mínimo exigido pelo Ministério da Educação, segundo o cadastro de instituições de Ensino Superior do órgão. Eram 71 instituições com Índice Geral de Cursos (IGC) de número 4 - nenhuma tinha índice 5, o mais alto da escala. Outras 46 instituições (10\%) não tinham conceito. O IGC é calculado a partir da rnédia dos três últimos anos dos resultados do Conceito Prelirninar de Curso (CPC). Esse índice, por sua vez, leva em conta a avaliação feita pelos alunos, o Exarne Nacional de Desempenho dos Estudantes (Enade) e a análise da infraestrutura e do corpo docente. O conceito 3 no IGC é o rnínimo para que urna instituição funcione, de acordo com a regulação do setor. Em 2013, 72\% de 1.568 instituições de Ensino Superior no país tinham IGC 3. Só 4\% chegaram a um indicador 4 ou 5 (BURGARELLI, 2017. p. 45).

13. Disponível em: http://fepesp.org.br/noticia/kroton-gigante-se-reorganiza-de-olho-na-educacao-basica/. Acesso em: 22 jul. 2020. 
14. Uma importante referência dessa intensificação da mercantilização da educação superior no início do novo século está expressa no documento do Banco Mundial intitulado Construir Sociedades de Conocimiento: Nuevos Desafíos para la Educación Terciaria, publicado em 2002. "Incrementen la diversificación institucional (aumento del número de instituciones no universitarias y privadas) para ampliar la cobertura sobre una base financiera viable y para establecer un marco de formación continua con múltiples puntos de acceso y gran variedad de itinerarios formativos" (BANCO MUNDIAL, 2002, p. 27; em tradução livre, "incrementem a diversificação institucional [aumento do número de instituições não universitárias e privadas] para ampliar a cobertura sobre uma base financeira viável e para estabelecer um marco de formação contínua com múltiplos pontos de acesso e grande variedade de itinerários formativos).

\section{Referências}

BANCO MUNDIAL. Relatório Anual. Exercícios Fiscal 2009. Washington: INT, 2009. Disponível em: http://webcache.googleusercontent.com/search?q=cache:2dvoFgT4kEEJ:pubdocs.worldbank.org/pubdocs/ publicdoc/2015/12/492601449168542396/INT-FY09-Annual-Report-Portuguese.pdf $+\& c d=1 \&$ hl=ptBR\&ct=clnk\&gl=br. Acesso em: 27 jun. 2020.

BANCO MUNDIAL. Construir sociedades de conocimiento: nuevos desafíos para la educación terciaria. Washington: Branco Mundial, 2002. Disponível em: http://siteresources.worldbank.org/EDUCATION/ Resources/278200-1099079877269/547664-1099079956815/CKS-spanish.pdf. Acesso em: 22 jul. 2020.

BITTAR, M. O Ensino Superior privado no Brasil e a formação do segmento das universidades comunitárias. Avaliação: Revista da Avaliação do Ensino Superior, Campinas, v. 6, n. 2, p. 33-42, jun. 2001.

BRASIL. Constituição da República Federativa do Brasil de 1988. São Paulo: Peres, 1992.

BRASIL. Lei n. 9.131, de 24 de novembro de 1995. Altera dispositivos da Lei n. 4.024, de 20 de dezembro de 1961, e dá outras providências. Diário Oficial da União: edição extra, Brasília, DF, 25 nov. 1995. Disponível em: http://www.planalto.gov.br/ccivil_03/leis/19131.htm. Acesso em: 13 mar. 2020.

BRASIL. Lei de Diretrizes e Bases da Educação Nacional. Cascavel: UNIOESTE, 1997.

BRASIL. Lei n. 10.406, de 10 de janeiro de 2002. Institui o Código Civil Brasileiro. Diário Oficial da União. Brasília, DF, 11 jan. 2002. Disponível em: http://www.planalto.gov.br/ccivil_03/leis/2002/L10406.htm. Acesso em: 12 mar. 2020.

BRASIL. Lei n. 12.441, de 11 de julho de 2011. Altera a Lei n. 10.406, de 10 de janeiro de 2002 (Código Civil), para permitir a constituição de empresa individual de responsabilidade limitada. Diário Oficial da União, Brasília, DF, 12 jul. 2011. Disponível em: http://www.planalto.gov.br/ccivil_03/_ato2011-2014/2011/ lei/l12441.htm. Acesso em: 20 fev. 2020.

BRASIL. Lei n. 12.529, de 30 de novembro de 2011. Estrutura o Sistema de Defesa da Concorrência; dispõe sobre a prevenção e repressão às infrações contra a ordem econômica. Diário Oficial da União, Brasília, DF, 2 dez. 2011. Disponível em:http://www.planalto.gov.br/ccivil_03/_ato2011-2014/2011/Lei/L12529.htm. Acesso em:28 dez. 2019.

BRUNNER, J. J. Mercados universitarios: ideas, instrumentos y seis tesis en conclusión. Santiago de Chile., mar. 2006. Disponível em: https://pt.scribd.com/document/20048362/MERCADOS-UNIVERSITARIOSIDEAS-INSTRUMENTOS-Y-SEIS-TESIS-EN-CONCLUSION. Acesso em: 20 de março de 2019.

BUKHARIN, N. I. (1917) O imperialismo e a economia mundial. Trad. Aurélia Sampaio Leite. Rio de Janeiro: Editora Laemmert, 1969. 
BURGARELLI, R. Explosão e implosão do Fies: como o Ensino Superior privado virou o centro dos gastos com educação do Governo Federal. MARINGONI, G. et al. (orgs.). O negócio da educação: aventuras na terra do capitalismo sem risco. São Paulo: Olho d’Água/Fepesp, 2017.

CADE. Conselho Administrativo de Defesa Econômica. O que é o CADE. Disponível em: www.cade.gov. br. Acesso em: 16 fev. 2020.

CHAVES, V. L. J. Expansão da privatização/mercantilização do Ensino Superior brasileiro: a formação dos oligopólios. Educação \& Sociedade, Campinas, v. 31, n. 111, p. 481-500, 2010. https://doi.org/10.1590/ S0101-73302010000200010

CHESNAIS, F. O capital portador de juros: acumulação, internacionalização, efeitos econômicos e políticos. In: CHESNAIS, F. (org.). A finança mundializada. São Paulo: Boitempo, 2005.

CNTE [CONFEDERAÇÃO NACIONAL DOS TRABALHADORES EM EDUCAÇÃO]. A privatização da educação no contexto do golpe institucional no Brasil. Revista Retratos da Escola, Brasília, v. 11, n. 21, p. 745-751, jul.-dez. 2017. https://doi.org/ 10.22420/rde.v11i21.830

DURHAM. E. R. O Ensino Superior no Brasil: público e privado. São Paulo: Núcleo de Pesquisas sobre Ensino Superior da Universidade de São Paulo, 2003. (Documento de trabalho 3/03.)

HARVEY, D. A condição pós-moderna. São Paulo: Edições Loyola, 2008.

HARVEY, D. O Enigma do Capital e as crises do capitalismo. São Paulo: Boitempo, 2011.

IAMAMOTO, M. Serviço social no tempo do capital fetiche. 7. ed. São Paulo: Cortez, 2012.

INEP [INSTITUTO NACIONAL DE ESTUDOS E PESQUISAS EDUCACIONAIS ANÍSIO TEIXEIRA]. Sinopse Estatística do Ensino Superior 2005-2008. Brasília: Inep, 2019. Disponível em: http://inep.gov.br/ sinopses-estatisticas-da-educacao-superior. Acesso em: 16 fev. 2020.

ISTOÉ DINHEIRO. Os bárbaros chegaram ao portão, 04 abr. 2014. Disponível em: http://www.istoedinheiro. com.br/noticias/financas/20140404/barbaros-chegaram-portao/62993. Acesso em: 18 jun. 2019.

MARX. K. O Capital: crítica da economia política. 30. ed. Rio de Janeiro: Civilização Brasileira, 2012. livro I, v. 1.

MARX. K. O Capital. Trad. Rubens Ederle. São Paulo: Boitempo, 2016. livro III, v. IV.

MÉSZÁROS, I. A educação para além do capital. São Paulo: Boitempo, 2008.

MÉSZÁROS, I. A crise estrutural do capital. 2. ed. rev. e ampl. Trad. Francisco Raul Cornejo. São Paulo: Boitempo, 2011.

MÉSZÁROS, I. Para além do capital: rumo a uma teoria da transição. 1. ed. rev. Trad. Paulo Cezar Castanheira; Sérgio Lessa. São Paulo: Boitempo, 2011.

PANIAGO. M. C. S. O controle do capital: uma impossibilidade objetiva. Revista Serviço Social e Sociedade, São Paulo, n. 64. 2000.

PEREIRA, T. L. Monopolização do Ensino Superior privado no Brasil por meio de processos de fusões e aquisições: o grupo UNIESP em questão. Tese (Doutorado em Educação) - Faculdade de Educação, Universidade Federal de Mato Grosso do Sul, Campo Grande/MS, 2017. 
SAMPAIO, H. O setor privado de Ensino Superior no Brasil: continuidades e transformações. Revista de Ensino Superior da Unicamp, Campinas, n. 14, out. 2011. Disponível em: https://www.revistaensinosuperior. gr.unicamp.br/artigos/o-setor-privado-de-ensino-superior-no-brasil-continuidades-e-transformacoes. Acesso em: 22 jul. 2020.

SGUISSARDI, V. Educação superior no Brasil: democratização ou massificação mercantil? Educação \& Sociedade, Campinas, v. 36, n. 133, p. 867-889. 2015. https://doi.org/10.1590/ES0101-73302015155688

SGUISSARDI, V.; SILVA JÚNIOR, J. R. Trabalho intensificado nas federais: pós-graduação e produtivismo acadêmico. São Paulo: Xamã, 2009.

TAVARES, P. H. Os fundos de investimentos e o movimento do capital no Ensino Superior privado: mercantilização de novo tipo? Dissertação (Mestrado em ) - Faculdade de Educação, Universidade Federal do Rio de Janeiro, Rio de Janeiro, 2014.

\section{Sobre o Autor}

Tarcísio Luiz Pereira é doutor em Educação pela Universidade Federal de Mato Grosso do Sul (UFMS). Professor Adjunto da UFMS no Centro Pedagógico de Três Lagoas (UFMS/CPTL) e do Programa de Pós-graduação em Educação da UFMS/CPTL. Pesquisador e líder do Grupo de Estudos e Pesquisas em Formação de Professores (GFORP). Coordenador da linha de pesquisa "Políticas Educativas e Privatização da Educação Superior". 